\title{
Safety and pharmacological characterization of the molecular tweezer CLR01 - a broad-spectrum inhibitor of amyloid proteins' toxicity
}

\author{
Aida Attar ${ }^{1,2}$, Wai-Ting Coco Chan ${ }^{1}$, Frank-Gerrit Klärner ${ }^{4}$, Thomas Schrader ${ }^{4}$ and Gal Bitan ${ }^{1,2,3^{*}}$
}

\begin{abstract}
Background: The "molecular tweezer" CLR01 is a broad-spectrum inhibitor of abnormal protein self-assembly, which acts by binding selectively to Lys residues. CLRO1 has been tested in several in vitro and in vivo models of amyloidoses all without signs of toxicity. With the goal of developing CLR01 as a therapeutic drug for Alzheimer's disease and other amyloidoses, here we studied its safety and pharmacokinetics.
\end{abstract}

Methods: Toxicity studies were performed in 2-m old wild-type mice. Toxicity was evaluated by serum chemical analysis, histopathology analysis, and qualitative behavioral analysis. Brain penetration studies were performed using radiolabeled CLRO1 in both wild-type mice and a transgenic mouse model of Alzheimer's disease at 2-m, 12-m, and 22-m of age. Brain levels were measured from $0.5-72 \mathrm{~h}$ post administration.

Results: Examination of CLR01's effect on tubulin polymerization, representing normal protein assembly, showed disruption of the process only when 55-fold excess CLR01 was used, supporting the compound's putative "processspecific" mechanism of action.

A single-injection of $100 \mathrm{mg} / \mathrm{kg}$ CLR01 in mice - 2,500-fold higher than the efficacious dose reported previously, induced temporary distress and liver injury, but no mortality. Daily injection of doses up to $10 \mathrm{mg} / \mathrm{kg}$ did not produce any signs of toxicity, suggesting a high safety margin.

The brain penetration of CLR01 was found to be $1-3 \%$ of blood levels depending on age. Though CLR01 was almost completely removed from the blood by $8 \mathrm{~h}$, unexpectedly, brain levels of CLR01 remained steady over $72 \mathrm{~h}$.

Conclusion: Estimation of brain levels compared to amyloid $\beta$-protein concentrations reported previously suggest that the stoichiometry obtained in vitro and in vivo is similar, supporting the mechanism of action of CLRO1. The favorable safety margin of CLR01, together with efficacy shown in multiple animal models, support further development of CLR01 as a disease-modifying agent for amyloidoses.

Keywords: Molecular tweezers, Toxicity, Alzheimer's disease, Drug development, Blood-brain barrier

\section{Background}

Alzheimer's disease (AD) along with over 30 other diseases, are amyloidoses, in which aberrant protein folding and aggregation is a central pathologic process. Amyloidoses are characterized by self-assembly of one or more proteins into toxic oligomers and insoluble amyloid. Currently, amyloidoses have no cure. Inhibition of

\footnotetext{
* Correspondence: gbitan@mednet.ucla.edu

'Department of Neurology, David Geffen School of Medicine, University of California at Los Angeles, Los Angeles, CA 90095-7334, USA

${ }^{2}$ Brain Research Institute, University of California at Los Angeles, Los Angeles, CA 90095, USA

Full list of author information is available at the end of the article
}

the aberrant aggregation process is highly challenging because unlike traditional drug targets that have defined structures and in many cases, specific binding sites or active sites, toxic oligomers of amyloidogenic proteins are metastable structures that sample numerous conformations and amyloid fibrils are characterized by flat surfaces. These structures largely are devoid of specific binding pockets $[1,2]$. A possible solution to these challenges is to aim for one step prior to the unknown and unfavorable structures, specifically targeting the aberrantly self-associating proteins at the level of amino acid interactions. 
Recently, we reported that the molecular tweezer, CLR01, is a novel, broad-spectrum inhibitor of abnormal protein self-assembly, which acts by a "process-specific" mechanism and inhibits the aggregation and toxicity of multiple amyloidogenic proteins [3-5]. CLR01 is a small molecule, originally developed as an artificial Lys receptor $[6,7]$ that binds Lys residues with low micromolar affinity $[3,6]$ or in certain cases, sub-micromolar affinity [8]. The binding is highly labile [9], yet it is selective to Lys and involves inclusion of the Lys side-chain within the tweezer cavity (Figure 1). CLR01 also binds to Arg with $\sim 10$-fold lower affinity $[7,10]$. Selective binding to Lys is achieved by a combination of hydrophobic and electrostatic interactions. Lys is the only proteinaceous amino acid side-chain that effectively forms both types of interactions - hydrophobic interactions involving the butylene chain, and Coulombic attraction/repulsion of its $\varepsilon-\mathrm{NH}_{3}{ }^{+}$group. Both types of interactions are important in aberrant protein self-assembly. Thus, CLR01 competes for the same interactions that are key to nucleation and aggregation by most amyloidogenic proteins $[11,12]$.

The moderate-affinity binding of CLR01 to Lys is key to its process-specific mechanism. Unlike the forces that mediate normal protein biology, those that control the abnormal assembly of amyloidogenic proteins were not

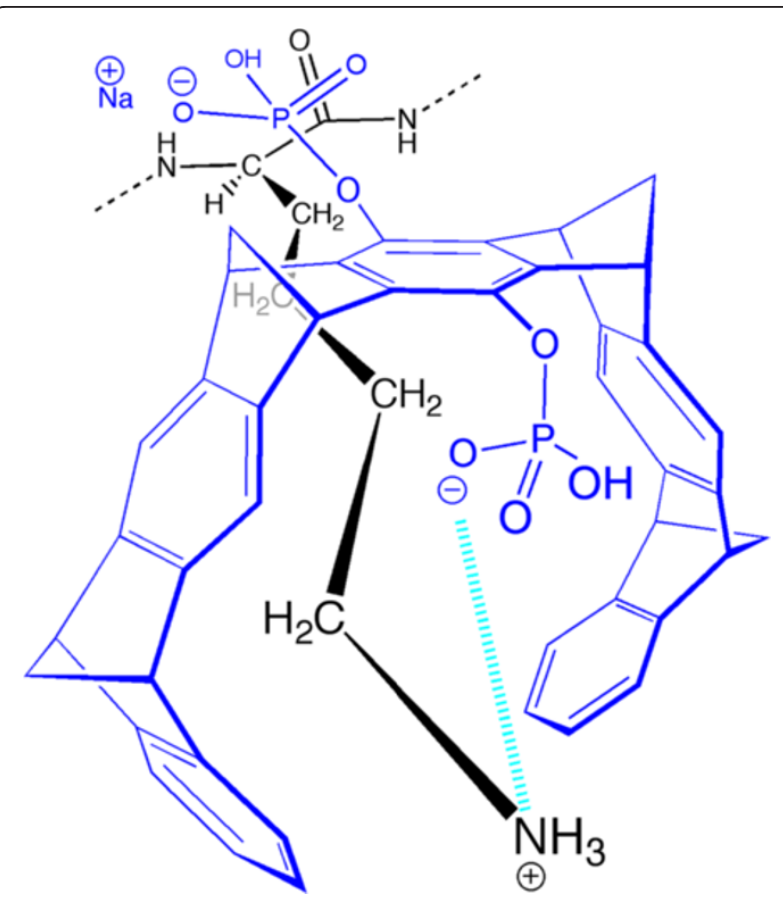

Figure 1 Schematic representation of the interaction between CLR01 and Lys. CLR01 is depicted in blue and Lys in black. The Coulombic attraction between a negatively charged phosphate group at the bridgehead of CLRO1 and the positively charged $\varepsilon-\mathrm{NH}_{3}{ }^{+}$ group of Lys is illustrated in cyan. The binding is stabilized also by hydrophobic interaction between the hydrocarbon side arms of CLR01 and the butylene chain of the Lys. optimized by evolution. Consequently, the binding energies involved are substantially weaker than those controlling normal protein structure and function. Therefore, although CLR01 may bind to exposed Lys residues in virtually any protein, we reasoned that at sufficiently low concentrations, labile binding with micromolar affinity would only affect relatively weak interactions, such as those that mediate aberrant protein oligomerization and nucleation.

The data generated to date have supported our conjecture. In vitro studies of metabolic toxicity and drug-drug interaction involving the cytochrome P450 system showed minimal inhibition of five major isoforms with half-maximal inhibition concentration values above levels expected to cause drug-drug interactions [5]. Minimal activation of the cytochrome P450 system by CLR01 was detected up to $10-\mu \mathrm{M}$ concentrations in a cell-culture system compared to the antibiotic rifampicin, which was used as a positive control [5]. In nerve growth factordifferentiated rat pheochromocytoma cells treated with CLR01, no toxicity was detected up to $200 \mu \mathrm{M}$, whereas a mild decrease in cell viability was observed at $400 \mu \mathrm{M}-1$ 3 orders of magnitude higher than concentrations needed for inhibition of the toxicity of different amyloidogenic proteins in cell culture $[3,13]$.

In vivo, CLR01 prevented deformation and mortality in a zebrafish model of $\alpha$-synuclein ( $\alpha$-syn) toxicity by keeping $\alpha$-syn soluble, preventing its neurotoxic effects, and promoting disinhibition of the $26 \mathrm{~S}$ ubiquitinproteasome system, thus allowing it to degrade the excess $\alpha$-syn [4]. Peripheral, subcutaneous (SC) administration of CLR01 in a triple-transgenic $(3 \times \mathrm{Tg})$ mouse model of $\mathrm{AD}$ [14] resulted in a significant decrease in amyloid plaque burden and hyperphosphorylated tau, with an accompanying decrease in microgliosis [5]. Similarly, peripheral administration of CLRO1 in a mouse model of familial amyloidotic polyneuropathy expressing mutant transthyretin led to a significant decrease in transthyretin deposition and associated endoplasmic-reticulum stress, apoptosis, and protein oxidation markers [15]. In support of the putative process-specific mechanism of CLR01, no signs of toxicity were observed in any of these studies. CLR01 was used at up to $10 \mu \mathrm{M}$ in the zebrafish model (in the water environment [4]), at $40 \mu \mathrm{g} / \mathrm{kg} /$ day in the AD mouse model [5], and at $1.2 \mathrm{mg} / \mathrm{kg} /$ day in the transthyretin model [15].

Further support for the proposed process-specific mechanism came from the observation that CLR01 did not affect processing of amyloid $\beta$-protein precursor (APP) in the treated AD mice. In APP, Lys residues are located $\mathrm{N}$-terminally to the $\alpha$ - and $\beta$-secretase cleavage sites. Ostensibly, CLR01 binding to these residues could have affected APP processing. However, no differences were found in levels of APP cleavage products between 
brain extracts of vehicle- or CLR01-treated mice [5]. To further examine the putative process-specific mechanism and toxicity profile of CLR01, here we evaluated the effect of the compound in vitro on a physiologic (as opposed to aberrant) protein self-assembly process-tubulin polymerization-and in vivo using wild-type (WT) mice to which CLR01 was administered at high doses either as a one-time bolus or daily for 1 month.

A large number of amyloidoses affect the central nervous system (CNS). If molecular tweezers are to be developed as drugs for these diseases, they likely will need to cross the blood-brain barrier (BBB). In the ADmouse-treatment study, SC administration of CLR01 resulted in clear CNS effects [5], suggesting that the compound penetrated through the $\mathrm{BBB}$ into the brain of the mice. However, in that study we only began to measure the brain penetration levels and did not address the effect of age or disease. The BBB becomes compromised with aging [16] and this compromise is thought to be exacerbated in patients with certain neurodegenerative diseases, including AD [17-19]. Previously, using ${ }^{3} \mathrm{H}-\mathrm{CLR} 01$ injected intravenously, we found radioactivity levels in the brain to be $\sim 2 \%$ of blood levels in 12 -m old WT and $3 \times \mathrm{Tg}$ $\mathrm{AD}$ mice [5]. We present here a characterization of the BBB's permeability to CLR01 and the effects of age and presence of $\mathrm{AD}$-linked transgenes. We also assess a likely route of metabolism of CLR01 in mouse brain.

\section{Methods}

\section{Mice}

All procedures were compliant with the National Research Council Guide for the Care and Use of Laboratory Animals, and approved by the University of California at Los Angeles (UCLA) Institutional Animal Care Use Committee. Two-month old WT C57BL/6J mice for toxicity studies were purchased from Jackson Laboratory (Bar Harbor, Maine, Stock 000664). 3×Tg and WT mice with the same genetic background [14] for BBB studies were bred at UCLA. Mice were housed 2-4 per cage under standard conditions and maintained on a 12-h dark and 12-h light cycle with ad libitum access to rodent chow and water.

\section{CLR01}

CLR01 was produced and purified as described previously [7]. ${ }^{3} \mathrm{H}$-CLR01 was prepared by Moravek Biochemicals (Brea, CA) using a method that provides ${ }^{3} \mathrm{H}$ incorporation into the hydrocarbon skeleton (i.e., nonlabile protons) [20] yielding pure ${ }^{3} \mathrm{H}$-CLR01 with specific activity $1.3 \mathrm{Ci} / \mathrm{mmol}$.

\section{Inhibition of tubulin polymerization}

The effect of CLR01 on tubulin polymerization [21,22] was analyzed using a commercial kit (Cytoskeleton, Inc.,
Denver, Colorado). Three $\mathrm{mg} / \mathrm{ml}$ porcine brain tubulin $(\sim 18 \mu \mathrm{M})$ were allowed to polymerize at $37^{\circ} \mathrm{C}$ in the absence or presence of CLR01 concentrations ranging from $10-1,000 \mu \mathrm{M}$. The turbidity of the solution was measured as absorbance at $\lambda=340 \mathrm{~nm}$ using a Synergy HT microplate reader (BioTek, Winooski, VT). The data are an average of three independent experiments with two wells per condition.

\section{Toxicity evaluation}

For acute-toxicity studies, 2-m old C57BL/6J mice were administered saline-vehicle, $10 \mathrm{mg} / \mathrm{kg}$, or $100 \mathrm{mg} / \mathrm{kg}$ CLR01 by a single intraperitoneal (IP) injection. The mice were sacrificed 24-h after the injection. For chronic toxicity studies, 2-m old C57BL/6J mice were administered saline-vehicle, $3 \mathrm{mg} / \mathrm{kg}$, or $10 \mathrm{mg} / \mathrm{kg}$ CLR01 by daily IP injection for 30 days. Acute-study mice were visually monitored for $1 \mathrm{~h}$ after injection and then every $50 \mathrm{~min}$ for $10 \mathrm{~min}$ over the first $6 \mathrm{~h}$ of the experiment for changes in activity and behavior. The mice also were monitored every $110 \mathrm{~min}$ for $10 \mathrm{~min}$ during the last $6 \mathrm{~h}$ of the experiment until they were sacrificed. Chronicstudy mice were monitored for $1 \mathrm{~h}$ after injection and then 3 times a day for $10 \mathrm{~min}$ each, every day of the first week. During that week there were no appreciable changes in the behavior, appearance, or weight of the mice. Therefore, monitoring was reduced to twice a day during the remainder of the experiment. On all occasions, the mice were monitored for any signs of severe toxicity, including bruising or bleeding, pale mucous membranes or extremities, diarrhea, dehydration, neurological signs, such as difficulty ambulating or paralysis, tachypnea or dyspnea, or abdominal distension.

Following the treatment, mice were anesthetized with pentobarbital and blood was collected by cardiac puncture and placed in tubes containing a clot activator for serum separation (Capiject T-MG tubes, Terumo Medical Products, Somerset, NJ). Then, the lungs were filled through the trachea with $4 \%$ paraformaldehyde to prevent collapse, and tissues (brain, heart-lung, liver, kidney, and spleen) were collected and fixed for $72 \mathrm{~h}$ in $4 \%$ paraformaldehyde at a ratio of $\sim 1: 10$ tissue:fixative $(\mathrm{v} / \mathrm{v})$. Tissues then were transferred into a $70 \%$-ethanol solution and transferred to the UCLA Mouse Pathology Core for paraffin embedding, sectioning, and tissue histopathology analysis. Serum was analyzed by the UCLA Division of Laboratory Animal Medicine (DLAM) Animal Serology \& Molecular Diagnostic Laboratory for an 11-panel serum chemical analysis using the ACE Alera Clinical Chemistry system (Alfa Wassermann Diagnostic Technologies, West Caldwell, NJ). The panel included: alanine aminotransferase, aspartate aminotransferase, albumin, alkaline phosphatase, creatinine, total bilirubin, lactate dehydrogenase, blood urea nitrogen, cholesterol, total protein, and glucose. 
Plasma concentration and blood-brain barrier permeability For studies of plasma concentration, CLR01 was administered by either SC or intravenous (IV) injection at $1 \mathrm{mg} / \mathrm{kg}$, or by oral gavage at $10 \mathrm{mg} / \mathrm{kg}$, and plasma was collected at time points between $0.33-24 \mathrm{~h}$. Three mice were used per time point. The concentration of CLR01 in plasma was determined by Wolfe Laboratories Inc. (Watertown, MA) using liquid chromatography-mass spectrometry (LC-MS) by interpolation of sample peak area data into the calibration curve.

The following groups of mice were used for CLR01 BBB penetration studies: $3 \times \mathrm{Tg}$ and the corresponding WT mice at 2-m, 12-m, and 22 - 24-m (hereafter referred to as 22-m) of age. The groups were: 2-m WT, 2-m Tg, 12-m WT, 12-m Tg, 22-m WT, 22-m Tg. Mice were administered ${ }^{3} \mathrm{H}$-CLR01 intravenously. Two $\mu \mathrm{Ci}$ per gram of mouse body weight, which are equal to $11.86 \mu \mathrm{g} / \mathrm{g}$ of CLR01 in which ${ }^{3} \mathrm{H}$-CLR01 made up 10\% of the total CLR01, were injected into the jugular vein. Blood and brain were collected at $0.5,1,3,8,24$, or $72 \mathrm{~h}$ (not all time points were collected for all groups, see the Results section). For times $\leq 3 \mathrm{~h}$, mice were anesthetized by IP injection of ketamine and xylazine. The mice remained anesthetized following the injection until the specified time point, at which point they were given a lethal dose of pentobarbital. Then, blood was collected via a cardiac puncture, and the brain harvested with or without a perfusion step Pharmacokinetics of CLR01 in vivo. For time points $8-72 \mathrm{~h}$, mice were not anesthetized and ${ }^{3} \mathrm{H}$-CLR01 was injected into the tail vein. This change was due to the difficulty of keeping mice anesthetized for longer than $3 \mathrm{~h}$. No differences were observed between mice given anesthesia and jugular vein injections and mice receiving tail vein injections.

Euthanasia procedures were the same as described above. For all mice, one hemisphere of the brain and $100-350 \mu \mathrm{l}$ of blood were separately digested following instructions from Perkin-Elmer (document: Scintillation Cocktails and Consumables) with $1 \mathrm{ml}$ Solvable (PerkinElmer, Waltham, MA), added to Ultima Gold Liquid Scintillation Cocktail (Perkin-Elmer) and read in a Triathler Liquid Scintillation Counter model 425-034, (Hidex, Turku, Finland). Brain permeability percentage was calculated as counts per minute (CPM) per $g$ of brain relative to CPM per $\mathrm{ml}$ of blood. The data are an average of values from three mice per genotype/age/time combination.

For CLR01 transport-saturation studies using $5 \times$ the CLR01 dose, ${ }^{3} \mathrm{H}$-CLR01 was kept at $10 \%$ of the total CLR01 mixture and a total of $59.3 \mu \mathrm{g}$ of CLR01 $(10 \mu \mathrm{Ci})$ per $\mathrm{g}$ of mouse body weight was injected IV (22-m WT $5 \times$ dose). For CLR01 brain-accumulation studies, two $11.86-\mu \mathrm{g} / \mathrm{g}$ injections were administered at equal time intervals $(22-\mathrm{m}$ WT $2 \times$ inj). In these experiments, mice were injected at time $=0$ and at $t=1 / 2$ of euthanasia time. For example, in the original, single-injection experiments, a mouse would receive an injection at $t=0$ and then be euthanized at $t=1 \mathrm{~h}$. In this experiment, a mouse received one injection at $t=0$, a second injection at $\mathrm{t}=0.5 \mathrm{~h}$, and then was euthanized at $\mathrm{t}=1 \mathrm{~h}$.

In experiments using ${ }^{3} \mathrm{H}$-CLR01, urine was collected when possible over the period between injection and euthanasia. In all cases, we found that the urine was radioactive. However, comparison among mice proved to be difficult. We could not normalize the radioactivity because the amount of urine in the bladder prior to injection and the volume produced during the experiment could not be calculated. Thus, we can simply conclude qualitatively that CLR01 is excreted through the urine, but cannot provide quantitative measures of what percentage of the compound is excreted this way.

\section{In vitro metabolism}

Potential dephosphorylation of CLR01 was analyzed by incubating $100 \mathrm{nmol}$ CLR01 with 0.08 units of alkaline phosphatase (ALP; calf intestinal alkaline phosphatase, Promega, Madison, Wisconsin) for $60 \mathrm{~min}$ at $60^{\circ} \mathrm{C}$. One enzymatic unit is defined as the amount of enzyme required for catalyzing the hydrolysis of $1 \mu \mathrm{mol}$ of $p$-nitrophenylphosphate per minute. $p$-Nitrophenylphosphate disodium salt at 5-50 nmol (Fisher, Waltham, Massachusetts) was used for generation of a standard curve. The amount of inorganic phosphate generated was measured spectrophotometrically using an EnzChek Phosphate Assay kit (Life Technologies, Carlsbad, California) according to the manufacturer's instructions on a DU-640 spectrophotometer (Beckman Coulter, Brea, California) at $\lambda=360 \mathrm{~nm}$. Baseline values were subtracted from readings and compared to the standard curve resulting from serial ALP reactions to calculate the amount of inorganic phosphate. Similarly, potential dephosphorylation of CLR01 by brain homogenates was measured. For these experiments, one brain hemisphere was homogenized by sonication in the presence of cOmplete proteaseinhibitor cocktail (Roche, Penzberg, Germany). Protein concentration was measured using a BCA Protein Assay Kit (Pierce, Rockford, Illinois). A "phosphate-mop" system was used according to the EnzChek Phosphate Assay kit instructions to sequester inorganic phosphates naturally present in $1.5 \mathrm{mg}$ of brain, and then 50-nmol CLR01 or different concentrations of $p$-nitrophenylphosphate disodium salt were added and incubated for $60 \mathrm{~min}$ at $60^{\circ} \mathrm{C}$.

\section{Statistics}

Data are shown as mean \pm SD or mean \pm SEM as appropriate. Statistical analysis was performed using Prism 6.0c (GraphPad, La Jolla, CA). For all experiments, 2way analysis of variance followed by Sidak's multiple 
comparisons test post-hoc analysis were used. The level of significance was set at $p<0.05$.

\section{Results}

\section{In vitro examination of the process-specific mechanism} of CLR01

As stated above, the mechanism by which CLR01 remodels the assembly of amyloidogenic proteins into non-toxic assemblies that can be degraded by normal clearance mechanisms is by its specific binding to Lys residues. The mechanism is "process-specific" because it is postulated to affect only the aberrant assembly of proteins that leads to toxic oligomers and aggregates, but not normal protein structure, function, or assembly as happens, e.g., in tubulin polymerization. To test whether this indeed is the case, we examined the effect of CLR01 on tubulin polymerization [21,22]. Three $\mathrm{mg} / \mathrm{ml}(\sim 18 \mu \mathrm{M})$ porcine brain tubulin, which contains $3.8 \%$ Lys and $4.8 \%$ Arg, was allowed to polymerize in the absence or presence of CLR01 concentrations ranging from 10-1,000 $\mu \mathrm{M}$.

In the absence of CLR01 or in the presence of up to $300 \mu \mathrm{M}$ of the compound, the change in turbidity followed a typical sigmoidal curve, starting at 0.05-0.09 absorbance units (Figure 2). The absorbance remained unchanged for the first 10-15 minutes, which is a typical lag phase in this reaction, and then increased gradually up to $\sim 60 \mathrm{~min}$, at which point the rate of increase began to decline, and the reaction was followed for another $10 \mathrm{~min}$. The only concentration at which significant modulation of the polymerization was observed was

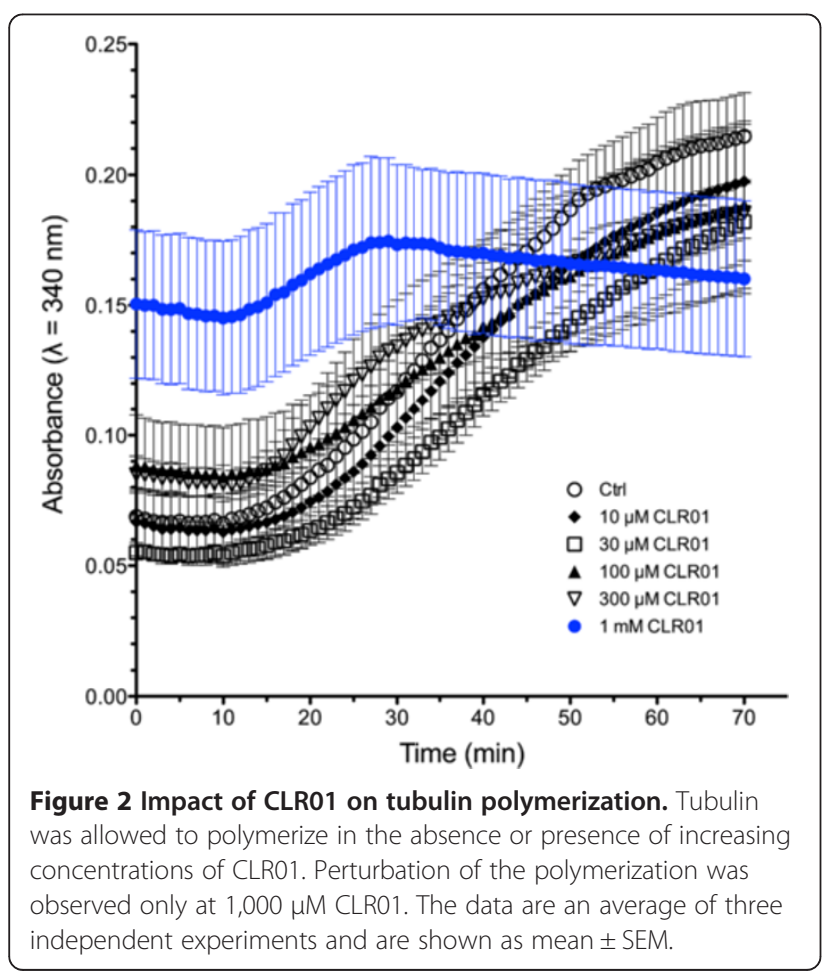

1,000 $\mu \mathrm{M}$ (Figure 2, blue curve), i.e., at a tubulin:CLR01 concentration ratio $\sim 1: 55$. At this high ratio, a high absorbance, 0.15 , was observed immediately, followed by a slight gradual decline during the lag phase. Then, the absorbance began to increase for $30 \mathrm{~min}$, followed by a slow decline for the rest of the experiment. One interpretation of these data is that at the high concentration used, 1,000 $\mu \mathrm{M}$, binding of CLR01 to tubulin induced immediate self-assembly into irregular aggregates. Similar immediate induction of self-assembly was observed with 4 of the 9 amyloidogenic proteins tested by Sinha et al. [3], suggesting that this reaction occurs with some, but not all proteins. In all the cases studied by Sinha et al., these aggregates were non-amyloidogenic and non-toxic.

Presumably, following the immediate aggregation in the presence of $1,000 \mu \mathrm{M}$ CLR01, the irregular tubulin aggregates observed at $\mathrm{t}=0$ partially disassembled as the polymerization reaction progressed, between $10-30 \mathrm{~min}$. At that point, the high CLR01 concentration appeared to interfere with the polymerization reaction and the tubulin polymers gradually disassembled. Validation of this interpretation will require further investigation, yet it was not the focus of the current study.

The motivation for this experiment was to test whether the concentration of CLR01 needed to interfere with a controlled self-assembly process was substantially different from that required for modulation of aberrant self-assembly, which was found indeed to be the case. Most of the protein:CLR01 concentration ratios needed for inhibition of amyloidogenic protein aggregation were in the range 1:1-1:3 [3], compared to the 1:55 tubulin: CLR01 concentration ratio at which disruption of tubulin polymerization was observed. These results support the specificity of CLR01 for inhibition of aberrant aggregation as opposed to controlled polymerization.

\section{CLR01 safety}

If CLR01 indeed operates by a process-specific mechanism and remodels the abnormal aggregation of amyloidogenic proteins at substantially lower concentrations than concentrations that would perturb normal physiological processes, one would expect the compound to have a high therapeutic index. To calculate the therapeutic index, a lethal dose must be reached. The in vitro data described above suggested that disruption of tubulin polymerization occurs at concentration ratios $20-50$ times higher than those needed for inhibition of aggregation of amyloidogenic proteins. In addition, cell culture experiments indicated that CLR01 began to show toxicity at concentrations 1-3 orders of magnitude higher than those required for inhibition of toxicity by different amyloidogenic proteins [3,4]. The next rational step was to test the safety margin of CLR01 in vivo. 
Based on the in vitro and cell culture data, we expected that $100 \mathrm{mg} / \mathrm{kg}$ would be lethal to mice and therefore used it as the highest dose in our safety-evaluation experiments. We assessed the safety of CLR01 in 2-m old, male, WT mice either $24 \mathrm{~h}$ following a single IP injection of 10 or $100 \mathrm{mg} / \mathrm{kg}$ (acute administration) or after daily IP injection of 3 or $10 \mathrm{mg} / \mathrm{kg}$ for 30 days (chronic administration). Following euthanasia, serum was collected for chemical analysis and tissues were harvested for histopathology evaluation.

All CLR01-treated groups, except for the $100-\mathrm{mg} / \mathrm{kg}$ acute-administration group, behaved indistinguishably from control mice in terms of levels and type of activity and grooming. The administration of $100-\mathrm{mg} / \mathrm{kg}$ CLR01 caused obvious signs of distress immediately, which lasted for $\sim 30 \mathrm{~min}$ following the injection. For most mice, activity level decreased and eyelids became droopy. Some of the mice exhibited arching of the back, sporadic gasping, lying down, dragging one leg, and twitching. These signs of distress diminished after the first $30 \mathrm{~min}$, at which point the mice resumed grooming and sitting on hind legs. Some mice showed decreased activity and droopy eyelids for up to $2 \mathrm{~h}$ following the injection. No symptoms of severe toxicity, as defined by the UCLA DLAM veterinarians, were observed for any mice, including bruising, bleeding, pale mucous membranes or extremities, diarrhea, paralysis, tachypnea or dyspnea, or abdominal distension.
Liver, kidney, spleen, heart, lung, and brain were collected for histopathology analysis. Tissue samples from heart, lung, spleen, and brain of all acutely CLR01administered mice were indistinguishable from those of control mice. In all $100-\mathrm{mg} / \mathrm{kg}$-dosed mice and one of eight $10-\mathrm{mg} / \mathrm{kg}$-dosed mice of the acute-administration groups, liver degeneration and necrosis was detected in centrilobular and midlobular regions (Figure 3). Zonal nature of liver toxicity is common in drug-toxicity studies and was expected in the high-dose group.

The fact that all the mice in the high-dose group survived meant that the actual therapeutic index could not be calculated because contrary to our expectation, $100 \mathrm{mg} / \mathrm{kg}$ was under the lethal dose. However, we considered the observation of obvious liver toxicity at this high dose as sufficient for determining the maximal dose in future efficacy experiments and therefore did not treat mice with higher doses. Rather, we conducted next a 30day, chronic-toxicity experiment in which mice were administered IP either 3 or $10 \mathrm{mg} / \mathrm{kg} /$ day of CLR01. Because one mouse of the eight used in the $10-\mathrm{mg} / \mathrm{kg}$ acute-administration group showed signs of liver toxicity, $10 \mathrm{mg} / \mathrm{kg} /$ day was chosen to be the highest dose in this experiment.

Heart, lung, spleen, and brain from both chronically CLR01-treated groups of mice were indistinguishable from vehicle-treated mice and were free of signs of malformation, degeneration, necrosis, or inflammation

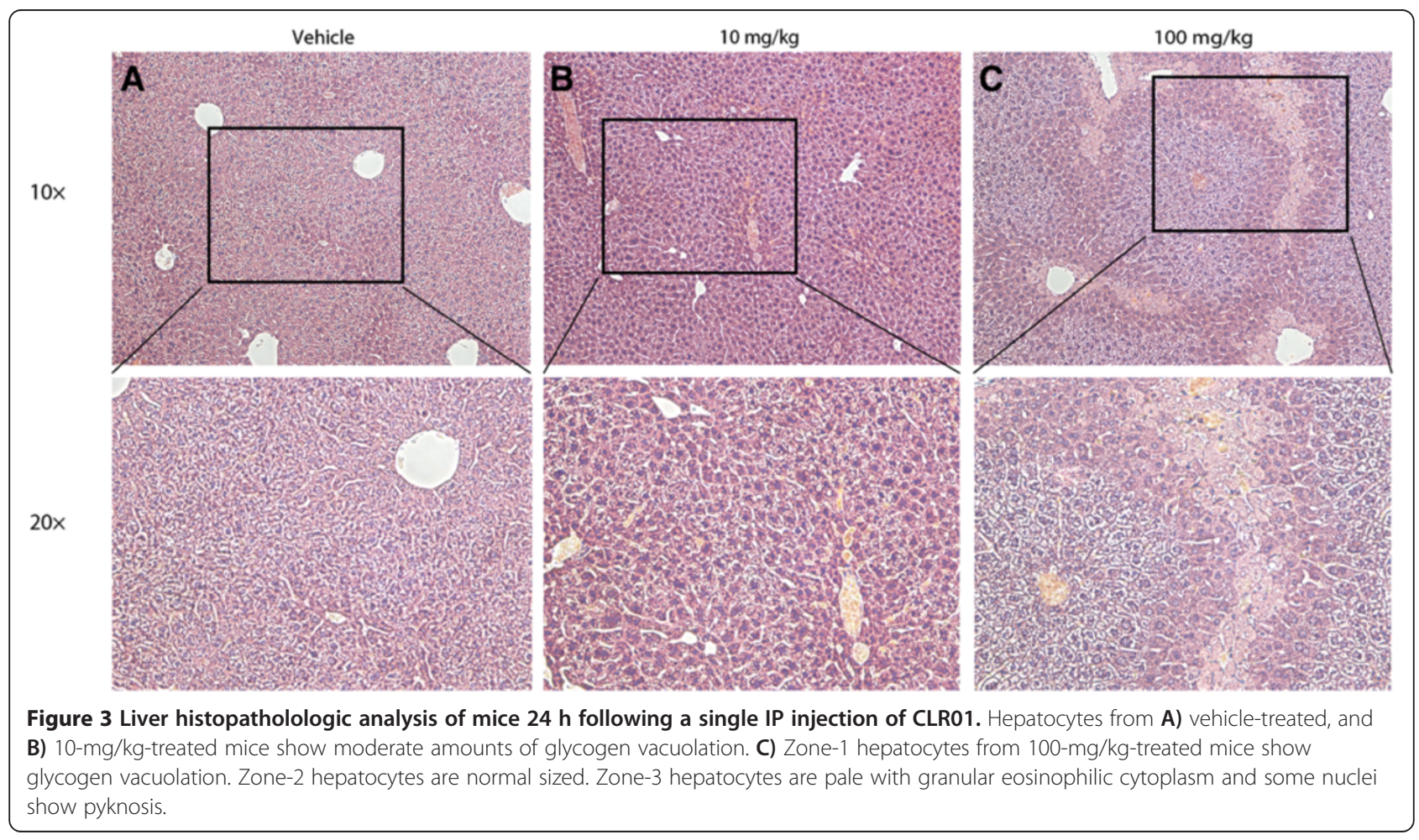


within normal variability among mice. A few mice in the 3-mg/kg group showed signs of mild-to-moderate multifocal extramedullary hematopoiesis in the liver. The consulting veterinary pathologist concluded that this was possibly immune-stimulated but not pathogenic. Mild pancreatitis also was observed in one of the mice showing liver hematopoiesis and one additional mouse in the $3-\mathrm{mg} / \mathrm{kg}$ group. In contrast, no signs of tissue pathology or liver necrosis were detected in any of the mice in the $10-\mathrm{mg} / \mathrm{kg}$ dosed group. Thus, it is unlikely that the hematopoiesis or inflammation found in the low-dose group were related to the CLR01 treatment.

Serum chemical analysis mainly consisted of tests of renal and liver function (Table 1). No significant differences were observed between the control and low-dose groups in either the acute-administration or chronicadministration experiments. The acute-administration, $100-\mathrm{mg} / \mathrm{kg}$ group showed significant increase in alanine aminotransferase, aspartate aminotransferase, and lactate dehydrogenase, and a significant decrease in cholesterol compared to both the control group and what is considered a normal range (UCLA DLAM, modified [23]). All of these changes are consistent with acute liver injury. Glucose levels were significantly lower in the $100-\mathrm{mg} / \mathrm{kg}$ acute-administration group than in the control group, but were within the normal range. Production of glucose is often the last function to be lost in liver damage. Other changes indicating liver damage, including changes in concentrations of albumin, alkaline phosphatase, or total bilirubin, were not observed. In the chronicadministration experiment, the only significant serumchemistry difference observed was $\sim 40 \%$ reduction in blood cholesterol in the $10-\mathrm{mg} / \mathrm{kg}$ group compared to the control group. The cholesterol level was within the normal range.

\section{Pharmacokinetics of CLR01 in vivo}

The plasma concentration of CLR01 was measured by LC-MS in 2-m old WT mice following administration by a SC or IV injection or by oral gavage. The SC bioavailability was found to be identical, within experimental error, to the IV administration, which was considered as $100 \%$ bioavailable (Figure 4 ). In both routes, $\sim 30 \%$ of the administered dose was detected in the blood at the earliest time point measured - $20 \mathrm{~min}$, and the plasma halflife was found to be $\sim 2.5 \mathrm{~h}$. Approximately $5 \%$ of the initial CLR01 levels were found in the plasma $8 \mathrm{~h}$ following either SC or IV administration. Oral bioavailability was negligible, suggesting that CLR01 gets metabolized in the gastrointestinal tract and/or does not pass from the gut to the blood.

Next, we asked what percentage of the administered CLR01 penetrates through the $\mathrm{BBB}$ and gets into the CNS. Our first attempt was to measure CLR01 in brain extracts using LC-MS. However, this proved to be difficult. Due to the multiple negative charges of CLR01, its partial protonation at physiologic $\mathrm{pH}$, and the presence of various counter-ions in biological fluids, the MS signal splits into multiple peaks resulting in low signal-tonoise ratio. The difficulty to observe the CLR01 signal in brain extracts using LC-MS suggested that the concentration was low and detection would necessitate considerable optimization of the extraction and LC-MS methods, which would require substantial effort and

Table 1 Serum analysis

\begin{tabular}{|c|c|c|c|c|c|c|c|}
\hline & & Acute, 2 & single dose & & Chronic, & day, daily & \\
\hline & & Control & $10 \mathrm{mg} / \mathrm{kg}$ & $100 \mathrm{mg} / \mathrm{kg}$ & Control & $3 \mathrm{mg} / \mathrm{kg}$ & $10 \mathrm{mg} / \mathrm{kg}$ \\
\hline & & $\mathrm{N}=3$ & $\mathrm{~N}=8$ & $\mathrm{~N}=8$ & $\mathrm{~N}=9$ & $\mathrm{~N}=10$ & $\mathrm{~N}=9$ \\
\hline & Normal range & Mean & Mean & Mean & Mean & Mean & Mean \\
\hline Alanine aminotransferase $\mathrm{U} / \mathrm{L}$ & $22-133$ & 30.7 & 36.1 & $1282.9^{* * *}$ & 52.1 & 43.1 & 38.4 \\
\hline Aspartate aminotransferase $U / L$ & $46-221$ & 63.3 & 89.5 & $565.3^{* *}$ & 367.0 & 150.9 & 236.2 \\
\hline Albumin $\mathrm{g} / \mathrm{dL}$ & $2.6-5.4$ & 2.2 & 2.3 & 1.9 & 2.8 & 2.8 & 2.7 \\
\hline Alkaline phosphatase $U / L$ & $16-200$ & 107.7 & 126.1 & 101.5 & 98.1 & 104.4 & 106.1 \\
\hline Creatinine $\mathrm{mg} / \mathrm{dL}$ & $0.1-1.8$ & 0.2 & 0.2 & 0.4 & 0.2 & 0.3 & 0.2 \\
\hline Total bilirubin mg/dL & $0.3-0.7$ & 0.2 & 0.2 & 0.3 & 0.3 & 0.2 & 0.2 \\
\hline Lactate dehydrogenase $\mathrm{U} / \mathrm{L}$ & $109-647$ & 235.0 & 325.2 & $2439.8^{* * *}$ & 486.6 & 507.0 & 483.0 \\
\hline Blood urea nitrogen $\mathrm{mg} / \mathrm{dL}$ & $2-71$ & 22.3 & 19.8 & 22.0 & 21.8 & 22.3 & 24.1 \\
\hline Cholesterol mg/dL & $34-173$ & 93.0 & 91.5 & $20.8^{* *}$ & 92.3 & 80.9 & $56.8^{* *}$ \\
\hline Total protein $\mathrm{g} / \mathrm{dL}$ & $4.6-7.3$ & 4.0 & 3.7 & 3.6 & 4.8 & 4.7 & 4.6 \\
\hline Glucose mg/dL & $60-133$ & 286.0 & 297.8 & $104.3^{* * *}$ & 250.6 & 256.7 & 233.9 \\
\hline
\end{tabular}

${ }^{* *} p<0.01$. ${ }^{* * *} p<0.001$

Values significantly different from the control group are highlighted in boldface. 


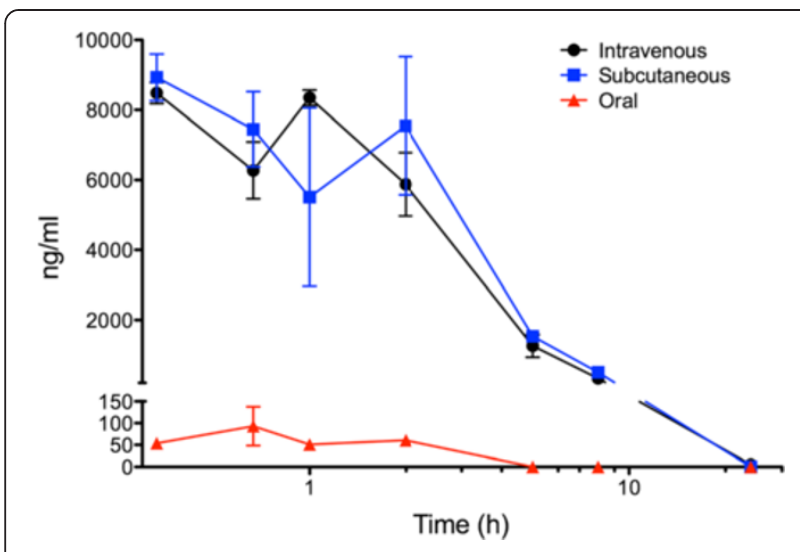

Figure 4 CLR01 plasma concentration following different routes of administration. The graph shows levels of CLR01 in plasma by intravenous (black line) or subcutaneous (blue line) injection at $1 \mathrm{mg} / \mathrm{kg}$, or by oral gavage (red line) at $10 \mathrm{mg} / \mathrm{kg}$ over $24 \mathrm{~h}$. Data are given as mean $\pm \mathrm{SD}$.

high costs. Therefore, we decided to test first whether CLR01 could be found in the CNS by using a radiolabeled derivative of the compound.

As the permeability of the BBB has been shown to be dependent on age and morbidity, and in particular to be increased in $\mathrm{AD}$ [17] and in mouse models of $\mathrm{AD}$ $[24,25]$, we assessed how age and disease progression affected the brain penetration of CLR01 by using WT and $3 \times \mathrm{Tg}$ mice at three different ages. The $3 \times \mathrm{Tg}$ model was chosen because it was used in a previous study, in which CLR01 was found to reduce AD-like pathology in the brain [5]. Mouse ages were chosen to correspond with: 1) a stage before $A \beta$ burden and cognitive deficits are found at $2-\mathrm{m}$ of age $[14,26] ; 2)$ a stage with mild-tomoderate plaque and tangle pathology but with observable memory deficits at 12-m of age [14,27]; and 3) a stage of abundant plaque and tangle pathology with consistent behavioral deficits at 22-m of age [28]. Mice were administered ${ }^{3} \mathrm{H}$-CLR01 IV, blood and brain were collected at time points between $0.5-72 \mathrm{~h}$ following CLR01 administration, and radioactivity levels were measured by liquid scintillation counting. Radioactivity is presented as CPM/g of brain or CPM/ml of blood.

To correct for the radioactivity associated with bloodborne ${ }^{3} \mathrm{H}$-CLR01 in the brain vasculature, we performed both perfusion and subtraction analyses. In perfusion experiments, WT and $3 \times \mathrm{Tg}$ mice at each of the three ages analyzed ( $\mathrm{n}=3$ per group) were perfused with phosphate buffered saline following euthanasia. Perfusion lasted for either $5 \mathrm{~min}$ or until the liver changed color from a red to yellow, whichever was longer. In other experiments, mice were not perfused, but radioactivity associated with $10 \mu \mathrm{l}$ of blood per g of brain $[29,30]$ was calculated based on brain weight and blood radioactivity levels and subtracted from brain radioactivity levels. At
$1 \mathrm{~h}$ post injection, perfusion-corrected brain values were statistically similar to subtraction-corrected brain values (Figure 5). Due to difficulties associated with the perfusion analysis, specifically liver color being used as an indirect readout of brain perfusion level, and because including a perfusion step could increase variability among experiments, the rest of the experiments utilized the subtraction method, which is a common practice in BBB-permeability studies $[29,30]$.

At $0.5 \mathrm{~h}$ following injection, blood radioactivity levels in $12-\mathrm{m}$ old mice were $39 \pm 13 \%$ and $40 \pm 6 \%$ of the injected levels, for $\mathrm{WT}$ and $3 \times \mathrm{Tg}$ mice, respectively. These values were in agreement with the CLR01 concentration levels detected in plasma by LC-MS. About 5 $10 \%$ of the radioactivity observed at time $0.5 \mathrm{~h}$ remained in the blood after $8 \mathrm{~h}$ (Figure 6).

Brain-radioactivity levels, calculated as a percentage of blood-radioactivity levels $(\mathrm{CPM} / \mathrm{g}) /(\mathrm{CPM} / \mathrm{ml})$ at $1 \mathrm{~h}$ following the injection ranged from $0.86-3.09 \%$ depending on age and genotype (WT versus $3 \times \mathrm{Tg}$, Figure 7 ). Analysis of brain penetration levels at $1 \mathrm{~h}$ by absence or presence of AD transgenes and by age showed a statistically significant effect of age but not of genotype. Interestingly however, $2-\mathrm{m}$ old $3 \times \mathrm{Tg}$ mice significantly differed from 12-m and 24-m old $3 \times \mathrm{Tg}$ mice (2-m: $3.09 \pm$ 0.55\%; 12-m: $1.43 \pm 0.17 \%$; 24-m: $1.45 \pm 0.28 \% ; p<0.05$ ), whereas in the WT group, the only significant difference was between the $2-\mathrm{m}$ and $24-\mathrm{m}$ old mice (2-m: $2.68 \pm$ 0.31\%; $12-\mathrm{m}: 2.11 \pm 0.69 \%$; $24-\mathrm{m}: 0.86 \pm 0.17 \% ; p<0.05$ ). This suggests that changes in BBB permeability occur earlier and more sharply in $3 \times \mathrm{Tg}$ mice compared to WT mice.

Surprisingly, although blood radioactivity levels declined rapidly (Figure 6), the radioactivity levels measured in the

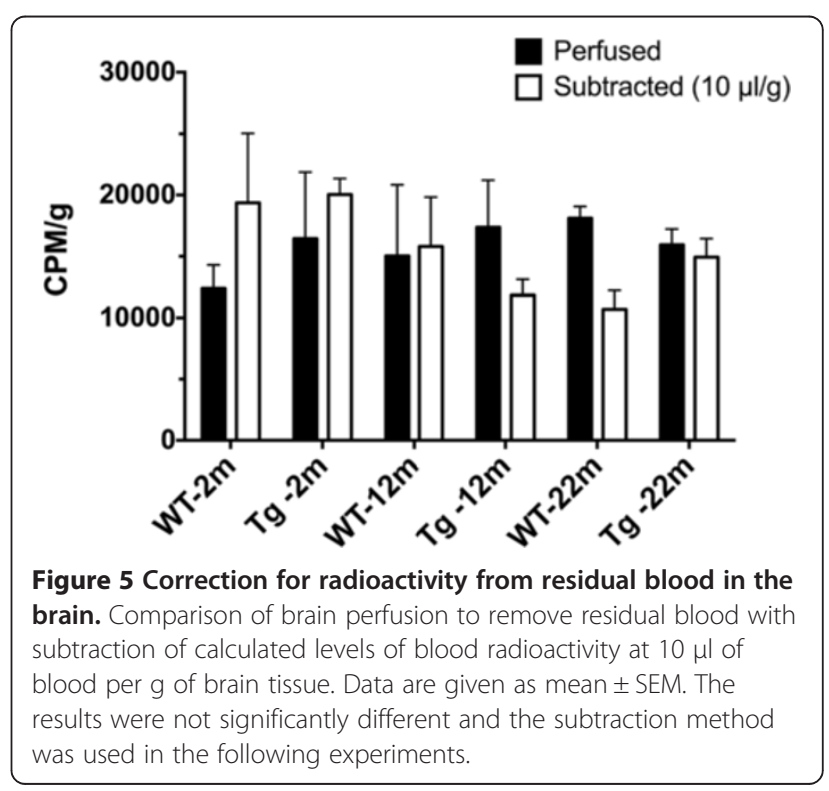




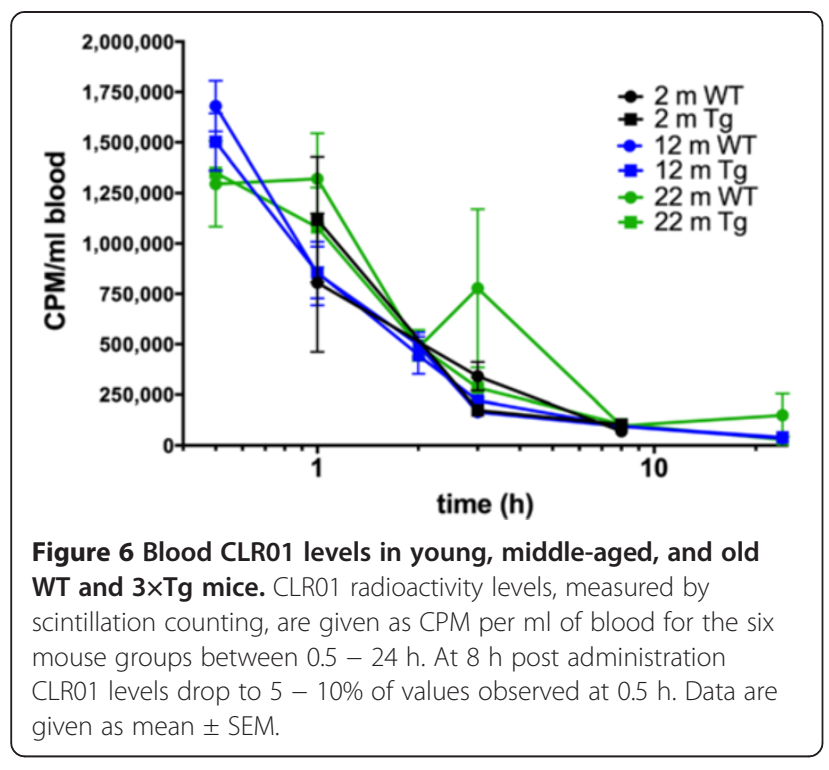

brain did not change significantly up to $72 \mathrm{~h}$ postinjection (Figure 8). Brain radioactivity levels were insensitive to genotype or time after injection and thus the 24-h time point was assessed only in the 22-m old mice (both $3 \times \mathrm{Tg}$ and WT) and the 72-h time point was assessed only in the 22-m old WT mice. Differences were statistically insignificant and within experimental error.

To explore further the mechanics of CLR01 transport across the BBB, we asked whether the transport system was saturated. To answer this question, we injected 5times the amount of total CLR01, keeping the ratio of ${ }^{3} \mathrm{H}$-CLR01:CLR01 at 1:9, into 22-m old WT mice. This experiment resulted on average, in 5-times the absolute amount of radioactivity detected in the brain. The percentage of brain penetration at $1 \mathrm{~h}$ following the injection

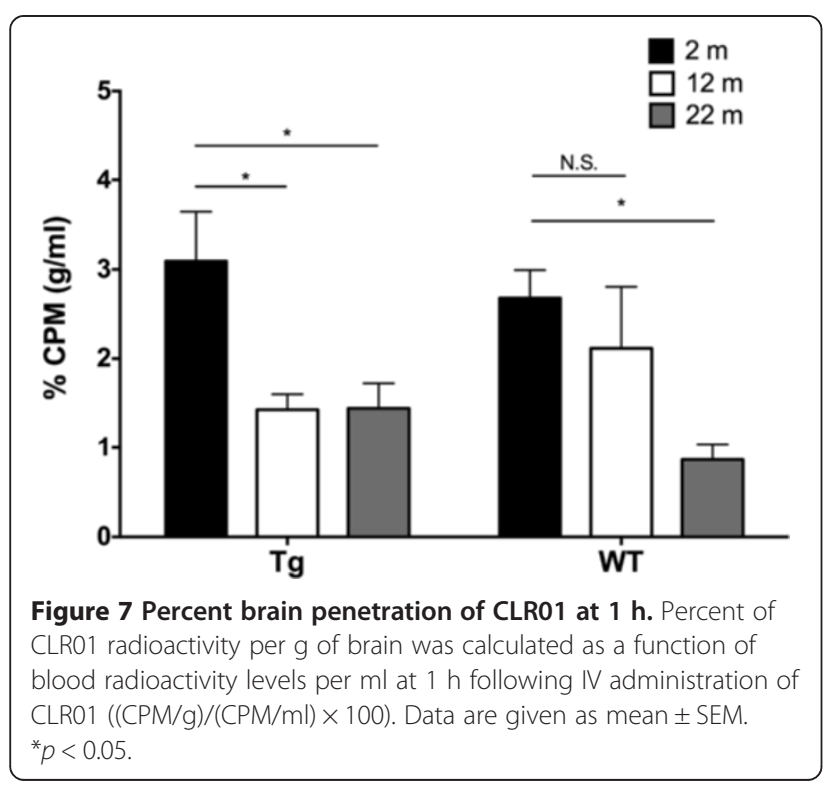



Figure 8 Brain CLR01 levels in young, middle-aged, and old WT and $3 \times \mathrm{Tg}$ mice. CLR01 radioactivity levels are given per $\mathrm{g}$ of brain. Most group $\times$ time combinations fall between 10,000 - 20,000 CPM/g (marked with red lines). Double injection studies in aged WT mice show on average double the radioactivity levels of single injection group, $22 \mathrm{~m} \mathrm{WT}$. Aged WT mice dosed with $5 \times$ the amount of CLR01, show on average 5 -times the radioactivity levels of the $1 \times$ group, $22 \mathrm{~m} \mathrm{WT}$. Data are given as mean \pm SEM.

did not change significantly $(1 \times$ CLR01 brain penetration: $0.86 \pm 0.30 \%$ of blood; $5 \times$ CLR01 brain penetration: $0.97 \pm$ $0.28 \%$ of blood; Figure 8 ). This result suggests that the transport mechanism, whether active or passive, is concentration-dependent because there was an increase in the absolute value but not the relative value of CLR01 entering the brain.

To begin to explore whether additional dosing would increase the effective CLR01 concentration in the brain, we injected 22-m old WT mice twice over two equal time intervals and compared brain levels to mice that received one injection. On average, over the 1-, 3-, and 8-h time points measured, the amount of radioactivity found in the brain following the double-injection was twice the amount measured following the single-injection protocol $(1 \mathrm{~h}: 3.3 \times$ compared to one injection, $3 \mathrm{~h}: 1.6 \times, 8 \mathrm{~h}$ : 1.9x; Figure 8). These data suggest that upon continuous dosing, as with the SC osmotic mini-pumps used in our previous efficacy study [5], CLR01 could reach sufficiently high brain concentration levels to inhibit $A \beta$ aggregation even though the dose was relatively low $40 \mu \mathrm{g} / \mathrm{kg} / \mathrm{day}$ - when brain penetration levels are taken into account (see Discussion).

\section{In vitro catabolism of CLR01}

The BBB permeability experiments described above used radioactivity as an indirect readout of CLR01 concentration levels, which could have reflected the parent compound, CLR01 itself, or its metabolites. The question of the source of radioactivity seemed particularly important 
in view of the surprising persistence of radioactivity attributed to CLR01 in the brain. The most likely metabolism of CLR01 is cleavage of one or both phosphate groups resulting in monophosphate and hydroquinone derivatives, respectively (Figure 9). Each such dephosphorylation would decrease the polarity of the compound and increase its potential partition into the lipophilic brain parenchyma environment relative to the blood. In particular, the hydroquinone product is insoluble in aqueous solutions, in contrast to CLR01 and its monophosphate metabolite, which are soluble at millimolar concentrations. Thus, double dephosphorylation could result in precipitation and accumulation of the hydroquinone in the brain, potentially leading to misinterpretation of the $\mathrm{BBB}$ permeability data. Complete analysis of CLR01 metabolism in the brain was beyond the scope of the study described here. However, to evaluate the potential for dephosphorylation, we incubated CLR01 in vitro with ALP or brain extracts and measured the release of inorganic phosphate.

ALP is a widely distributed plasma enzyme found in many tissues which can be released into body fluids [31]. The enzyme received its name because it shows optimal activity at $\mathrm{pH} \sim 9$. There are four isoforms of ALP: intestinal, placental, germ cell, and tissue non-specific. All four isoforms are non-specific enzymes that catalyze the hydrolysis of a wide range of phosphate esters [32]. Tissue non-specific ALP concentration levels increase in both brain and plasma of patients with familial or sporadic $\mathrm{AD}$ relative to age-matched healthy individuals [33], possibly as a compensatory mechanism because the enzyme catalyzes tau dephosphorylation [34].

Because of its promiscuous hydrolysis activity, we tested whether calf intestinal ALP catalyzed CLR01 dephosphorylation by incubating the molecular tweezer with ALP and comparing the amount of inorganic phosphate released to a standard curve obtained by incubating ALP with increasing concentrations of a common substrate, p-nitrophenylphosphate. This standard curve had a detection sensitivity limit of $5 \mathrm{nmol}$. Incubation of up to $100 \mathrm{nmol}$ CLR01 with ALP resulted in undetectable levels of inorganic phosphate, suggesting that despite its promiscuity, ALP did not catalyze dephosphorylation of CLR01.

To test whether CLR01 dephosphorylation might be catalyzed by brain phosphatases other than ALP, we incubated $50 \mathrm{nmol}$ CLR01 with $1.5 \mathrm{mg}$ of mouse-brain homogenate. The brain homogenate dephosphorylated the positive control substrate, p-nitrophenylphosphate, at $99-130 \%$ of the activity of 0.8 enzymatic units of ALP. In contrast, similarly to the reaction with ALP, no release of inorganic phosphate was detected when the brain homogenates were incubated with CLR01 under the same conditions. Based on these results, dephosphorylation of CLR01 likely did not happen in our BBB permeability experiments and the radioactivity measured in mouse brains plausibly reflected CLR01 itself.

\section{Discussion}

Recently, we have reported that CLR01, an inhibitor of aberrant assembly and toxicity of amyloidogenic proteins [3], protected primary neurons from $A \beta$-induced decrease in synaptic spine density, basal synaptic activity, and long-term potentiation [5]. In addition, CLR01 treatment of $15-\mathrm{m}$ old $3 \times \mathrm{Tg}$ mice with $40 \mu \mathrm{g} / \mathrm{kg} /$ day CLR01 for 28 days resulted in decreased AD-related brain pathology, including amyloid plaques, neurofibrillary tangles, and microglia levels [5]. In a mouse model of familial amyloidotic polyneuropathy, CLR01 significantly decreased transthyretin deposition and associated pathological markers, including ER stress, oxidative stress, and apoptosis [15]. Following up on these promising efficacy data, here, we explored the putative process-specific mechanism of CLR01, its safety margin in mice, its BBB permeability and how it might be affected by age and disease, and the most likely route of CLR01 metabolism.

As stated above, no signs of toxicity have been observed in in vivo efficacy studies. Towards determining optimal dosing for subsequent studies, we sought to find out the lethal dose, which would provide an upper limit

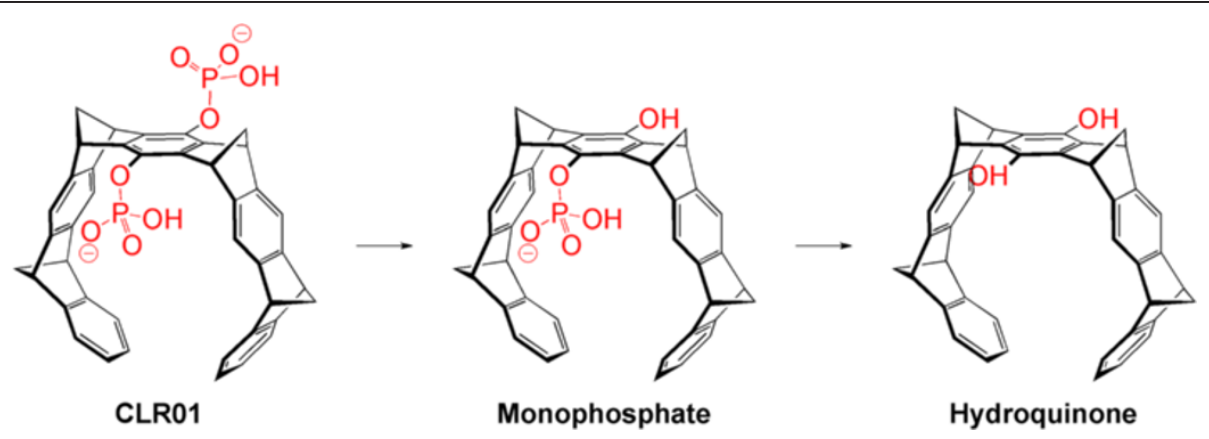

Figure 9 CLR01 dephosphorylation. Molecular structure of theoretical successive CLR01 dephosphorylations at the bridgehead to monophosphate and then to hydroquinone. 
for future dosing decisions. Effectively, we found that our highest acute dose of $100 \mathrm{mg} / \mathrm{kg}$ was not lethal but did elicit obvious behavioral signs of distress and liver damage (Table 1). Thus, chronic dosing at this concentration could lead to mortality. Importantly, we found that high doses of CLR01 had no effect on brain, heart, lung, spleen, or kidney. Liver injury, found by both histology and serum analysis, was the main indicator of acute toxicity. These data will be used to direct monitoring for potential toxicity in future studies using higher doses than those used previously and potentially using species other than mouse.

In the chronic-administration experiment, the only meaningful finding was a decrease in cholesterol levels, which were still within the normal range, in the 10-mg/ $\mathrm{kg}$ /day group (Table 1). This was an unexpected effect of CLR01 treatment, and may be of interest for further exploration especially for dual treatment of $\mathrm{AD}$ as high cholesterol in middle age is associated with increased risk for $\mathrm{AD}[35,36]$. Importantly, the chronically administered dose of $10 \mathrm{mg} / \mathrm{kg} /$ day is 250-times higher than the efficacious dose of $40 \mu \mathrm{g} / \mathrm{kg} /$ day used in the $\mathrm{AD}$ model [5] and thus provides a large safety margin. In support of this conclusion, concentrations up to $300 \mu \mathrm{M}$ did not significantly affect the polymerization of tubulin in vitro (Figure 2), suggesting that CLR01 does not inhibit physiologic protein assembly unless the concentrations used are substantially higher than those needed for therapeutic effects.

Several previous observations support the safety of CLR01. As mentioned above, in vivo, CLR01 decreased significantly brain $A \beta$ deposition without interfering with APP processing [5], and inhibited $\alpha$-synuclein aggregation but not its ubiquitination, which requires free Lys residues [4]. In addition, when CLR01 was tested in vitro as an inhibitor of enzymatic activity, the CLR01:enzyme concentration ratio needed for inhibition was orders of magnitude higher than the ratios needed for inhibition of abnormal protein aggregation. Thus, CLR01 inhibited alcohol dehydrogenase $(\mathrm{ADH})$ activity with $\mathrm{IC}_{50}=$ $180 \mu \mathrm{M}$ at $\mathrm{ADH}$ concentration of $208 \mathrm{nM}$ [7]. Thus, the CLR01:ADH ratio needed for inhibition was 865:1. In another study, CLR01 was tested as an inhibitor of Poly [ADP-ribose] polymerase 1 (PARP-1). Inhibition was found with an $\mathrm{IC}_{50}$ of $3.3 \mu \mathrm{M}$ at an enzyme concentration of $2.3 \mathrm{nM}$ (T. Schrader, unpublished results). The ratio in this case was $1435: 1$. These findings support the proposed process-specific mechanism and the development of molecular tweezers in general, and CLR01 in particular, towards initiation of clinical trials.

It is important to note that animal dose should not be extrapolated to a human equivalent dose by conversion of body weight, but rather by normalization to body surface area [37]. This method correlates well with several parameters of biology, including oxygen utilization, caloric expenditure, basal metabolism, blood volume, circulating plasma proteins, and renal function [38]. An extrapolation using the body surface area suggests that a dosing window between $0.04-10 \mathrm{mg} / \mathrm{kg} /$ day in mice corresponds to $0.003-0.81 \mathrm{mg} / \mathrm{kg} /$ day in humans.

Many of the properties of the BBB that determine the extent to which drugs are taken up by the brain are known to be altered in $\mathrm{AD}$, such as disruption of tight junctions, decreased CSF reabsorption, decreased cerebral blood flow, and decreased efflux pump activity [17]. Similar BBB compromise has been reported in animal models of $\mathrm{AD}[24,25]$, thus, we set out to explore the differences in CLR01 brain penetration in both WT and the $3 \times \mathrm{Tg}$ mouse model of AD. Because many of these properties, such as CSF reabsorption and BBB disruption, are not simply binary, we chose animals at three different ages, from 2 - 22-m, which correlate with different stages of disease progression, to evaluate the effect of age and disease on drug uptake. Using ${ }^{3} \mathrm{H}$-labeled CLR01, we found brain penetration levels between 1 $3 \%$ in the different ages, whereas the absence or presence of AD transgenes had little effect on CLR01 uptake into the brain (Figure 7). There was no statistically significant interaction between age and presence of $\mathrm{AD}$ transgenes. However, we did find that $2-\mathrm{m}$ old $3 \times \mathrm{Tg}$ mice differed significantly from $12-\mathrm{m}$ and $22-\mathrm{m}$ old $3 \times \mathrm{Tg}$ mice. In comparison, in the WT group, the only significant difference was between the 2-m and 22-m old mice. These data suggest that the presence of the ADrelated transgenes expedites the disintegration of the $\mathrm{BBB}$ and thus increases the brain penetration of CLR01 by a small, yet potentially meaningful, amount. Unexpectedly, we found higher penetration of CLR01 in the brains of the younger mice. One possible explanation of these findings, assuming that CLR01 enters the brain by a passive transport mechanism, is that the increased BBB permeability observed at old age results in faster leakage of CLR01 out of the brain than in the young mice. Alternatively, CLR01 may be taken up by a serendipitous active transport system that is more efficient in younger, than in older mice.

The observation that brain radioactivity did not decline with time (Figure 8) was peculiar. Linear regression analysis of the values between $1-72 \mathrm{~h}$ for the 22-m old WT mice resulted in a slope that was not significantly different from zero. This unexpected behavior raised a concern for a systematic error producing these data. However, both the double-injection-, and the $5 x$-doseexperiments showed a linear increase in brain radioactivity, suggesting that the radioactivity measured in the brain reflected bona fide uptake of CLR01 through the $\mathrm{BBB}$. Another concern was that the radioactivity measured in the brain actually came from residual blood that 
was not accounted for by either perfusion or subtraction of the expected values. However, the observations that blood CLR01 or ${ }^{3} \mathrm{H}$-CLR01 decreased to $\sim 5 \%$ of the starting values by $8 \mathrm{~h}$ (Figures 4 and 6) without a correlating decrease in brain radioactivity, which remained steady over that same period, indicated that the radioactivity measured in the brain was not related to residual blood levels. In addition, actual sample counts $(\geq 500$ CPM) were well above the minimum sensitivity of the liquid scintillation counting system (background was $<150$ CPM). Thus, the radioactivity measured in the brain reflected the actual ${ }^{3} \mathrm{H}$-CLR01 levels that penetrated the brain.

The observation that CLR01 penetration levels were consistent among groups and persistent over time suggests that CLR01 enters the brain and accumulates with parameters that are age-specific, as age was found to be a significant determinant of $\mathrm{BBB}$ penetration (Figure 7). One possible mechanism by which CLR01 passes across the $\mathrm{BBB}$ is by binding to Lys residues on receptors that span the membrane or get endocytosed. An analysis of the amino acid sequence of four major human cellular receptors involved in transferring cargo across the BBB transferrin, low density lipoprotein receptor-related protein 1 , glucose transporter 1 , and large neutral amino acid transporter - reveals that Lys makes up 3.3-6.6\% of their sequences. If these Lys residues are exposed and are positioned within the receptor's channel, or get endocytosed upon ligand binding, they may allow CLR01 to "hitchhike" its way across the BBB through its labile binding to these receptors and potentially through the transport of the natural cargo.

An important question is whether the mechanism of action of CLR01 in vivo is similar to, or different from, its mechanism in vitro. Though complete characterization of the in vivo mechanism is difficult to achieve, an important question is whether the stoichiometry of the molecular tweezer and its target proteins is similar in vitro and in vivo. Based on experiments using SC pumps in which $0.7 \%$ of the administered CLR01 was in the blood at steady-state (Lopes DHJ, Attar A, Du Z, McDaniel K, Dutt S, Bravo-Rodriguez K, RamirezAnguita JM, Sancez-Garcia E, Klärner F-G, Wang C, Schrader T, Bitan G: The molecular tweezer CLR01 inhibits islet amyloid polypeptide assembly and toxicity via an unexpected mechanism, submitted), the brain penetration of $\sim 2 \%$ of blood levels found here, and the efficacy studies in the $15-\mathrm{m}$ old $3 \times \mathrm{Tg}$ mice using a $40-\mu \mathrm{g} /$ $\mathrm{kg} /$ day dose [5], we estimate that $\sim 200 \mathrm{fmol}$ of CLR01 enter the brain per day. A literature search for brain concentration levels of $A \beta 40$ and $A \beta 42$ resulted in reported values from zero to a maximum of $280 \mathrm{fmol} / \mathrm{mg}$ brain [14]. The masses of the mouse brains used in our studies were $\sim 0.5 \mathrm{~g}$. Thus, a total of $\sim 140$ fmol A $\beta$ may be found at a given point in $13-\mathrm{m}$ old $3 \times \mathrm{Tg}$ mice [14]. Upon accumulation of CLR01 in the brain, as we observed in the double-injection experiment, the concentration levels of CLR01 entering the brain at a $40-\mu \mathrm{g} / \mathrm{kg} /$ day dose and of $\mathrm{A} \beta$ are expected to be on the same order of magnitude, specifically, in the range of hundreds of fmols. This is not to suggest that CLR01 does not interact with all exposed Lys residues on any protein. It likely does. However, whereas the high on-off rate of CLR01 binding to Lys residues [9] is unlikely to disrupt stable protein structures significantly, because self-association of amyloidogenic proteins depends on the improbable formation of a nucleus comprising multiple monomers, presumably binding of CLR01 to a small percentage of the monomers would be sufficient for disruption of nucleus formation. The same rationale is applicable to formation of metastable toxic oligomers, which are made of multiple monomers. Thus, substoichiometric concentrations of CLR01 relative to its target protein are expected to be sufficient for producing a beneficial effect. The analysis outlined above suggests that the intracranial A $\beta$ :CLR01 stoichiometry achieved in our in vivo study, in which we found substantial decrease in AD-like pathology [5], was similar to the stoichiometry in in vitro and cell culture experiments [3] providing strong support for the putative mechanism of action of CLR01.

The estimate of $200 \mathrm{fmol}$ of CLR01 entering the brain per day upon administration of $40 \mu \mathrm{g} / \mathrm{kg} /$ day [5] is a conservative one, when considering two additional factors. First, the levels of CLR01 detected in the plasma following an IV injection, which is considered 100\% bioavailable, were about $30 \%$ of amount injected. Thus, the amount detected may reflect the limitation of the detection method and the CLR01 actual concentration in the blood may be higher. Second, the cerebrovascular volume of the $3 \times \mathrm{Tg}$ mice at $11-\mathrm{m}$ of age has been shown to be $26 \%$ lower than that of non-transgenic littermates, potentially due to cerebrovascular amyloid deposition [39]. We did not take this difference into account in our correction for cerebral blood when calculating brain radioactivity and thus might have biased our data to reflect lower radioactivity in the older $3 \times \mathrm{Tg}$ mice than actual values. Taking these potential biases into account lends additional support to the suggested mechanism of action of CLR01 in vivo.

An important factor for development of CLR01 and/or other molecular tweezer derivatives as therapeutic drugs is identifying the active pharmaceutical ingredient. In vitro data suggest that binding of CLR01 itself to free Lys residues is what modulates the self-assembly of amyloidogenic proteins into non-amyloidogenic, non-toxic species. However, in vivo, CLR01 may be metabolized in currently unknown ways and the active pharmaceutical 
ingredient may be a metabolite. To examine potential CLR01 metabolism, previously, we tested the stability of the compound in mouse and human, plasma and liver microsomes and found $100 \%$ stability in all preparations [5]. To explore the question of stability and potential metabolism further, here, we hypothesized that the phosphate groups would be the most likely targets of metabolism and therefore asked whether they were substrates for dephosphorylation by ALP or other brain phosphatases. The question was of particular importance in view of the reported increase in ALP concentration in both brain and plasma of patients with $\mathrm{AD}$ relative to healthy individuals [33]. We tested the potential dephosphorylation of CLR01 under stringent conditions of excess ALP in buffer and did not find release of inorganic phosphate upon incubation of CLR01 with either the purified phosphatase or the brain extracts. A plausible explanation for the observed stability of CLR01's phosphate groups to enzymatic dephosphorylation is the rigid structure of the hydrocarbon backbone of the compound (Figures 1 and 9), which likely prevents its accommodation in the active sites of phosphatases.

Process-specific modulation of amyloid protein assembly is a useful approach that can be adopted for a multitude of amyloidoses. The beneficial therapeutic effects of CLR01 have been demonstrated in mouse models of AD and familial amyloidotic polyneuropathy, and a zebrafish model of Parkinson's disease [11]. Here, we found a favorable safety profile and small yet persistent brain penetration - a formidable starting point for future formal development of CLR01 towards human therapy.

\section{Conclusion}

A single dose of CLR01, at 2,500-fold the efficacious dose, induced behavioral distress and liver injury, but did not result in mortality. Daily dosing at 250 -fold the efficacious dose did not result in any signs of behavioral, serological, or pathological toxicity. In vitro evaluation of CLR01's influence on physiologically normal protein assembly did not show disruption until 55 -fold excess of CLR01 was used. These results indicate a high safety margin for CLR01. Brain penetration of CLR01 was observed to be $\sim 2 \%$ of blood levels depending on age, yet it was persistent for 3 days. These data were used to verify that sufficient levels of CLR01 are present in the brain for the putative mechanism of action.

\footnotetext{
Abbreviations

3xTg: Triple transgenic; a-syn: a-synuclein; AD: Alzheimer's disease; APP: Amyloid $\beta$-protein precursor; ALP: Alkaline phosphatase; BBB: Bloodbrain barrier; CNS: Central nervous system; CPM: Counts per minute; DLAM: Division of Laboratory Animal Medicine; IP: Intraperitoneal; IV: Intravenous; LC-MS: Liquid chromatography-mass spectrometry; SC: Subcutaneous; SEM: Standard error of the mean; WT: Wild type.
}

\section{Competing interests}

AA and WTCC have no competing interests to declare. FGK, TS, and GB are co-authors and co-inventors of International Patent Application No. PCT/ US2010/026419, USA Patent Application No. 13/203,962, European Patent Application 10708 075.6. GB is a Director and a Co-Founder of Clear Therapeutics, Inc.

\section{Authors' contributions}

$A A$ and $G B$ conceived and designed the research, analyzed the data, and wrote the manuscript. AA, WTCC, and GB performed the research. FGK and TS contributed reagents. All authors read and approved the final manuscript.

\section{Acknowledgements}

We thank Drs. Nora Rozengurt, Gregory Lawson, and Rachita Sumbria, University of California at Los Angeles, for critical suggestions and helpful discussions, Dr. David Teplow for the use of his plate reader, and Ms.

Danielle Shapira for help with literature search for the amino acid sequences of cellular transporters. This work was supported by University of California at Los Angeles Jim Easton Consortium for Alzheimer's Drug Discovery and Biomarker Development (G.B.); RJG Foundation grant 20095024 (G.B.); a grant from the Cure Alzheimer's Fund; a Voucher from the NIH/NCATS UCLA CTSI Grant Number UL1TR000124 (G.B.); Individual Pre-doctoral National Research Service Award 1F31AG037283 (A.A.); an administrative supplement to NIH/ NINDS UCLA Morris K. Udall Parkinson Disease Research Center of Excellence P50 NS38367 (PI Marie-Francoise Chesselet, administrative supplement Co-PI G.B.); and a Pilot Research Award from NIH/NIEHS UCLA Center for GeneEnvironment in Parkinson's Disease P01 ES016732 (G.B.).

\section{Author details}

${ }^{1}$ Department of Neurology, David Geffen School of Medicine, University of California at Los Angeles, Los Angeles, CA 90095-7334, USA. ²Brain Research Institute, University of California at Los Angeles, Los Angeles, CA 90095, USA. ${ }^{3}$ Molecular Biology Institute, University of California at Los Angeles, Los Angeles, CA 90095, USA. ${ }^{4}$ Institute of Organic Chemistry, University of Duisburg-Essen, Essen 45117, Germany.

Received: 7 February 2014 Accepted: 7 April 2014

Published: 16 April 2014

\section{References}

1. Highlights R: Chemical biology: aggravating aggregating. Nature 2008 , 451:608-609.

2. Roberts BE, Shorter J: Escaping amyloid fate. Nat Struct Mol Biol 2008, 15:544-546.

3. Sinha S, Lopes DH, Du Z, Pang ES, Shanmugam A, Lomakin A, Talbiersky P, Tennstaedt A, McDaniel K, Bakshi R, Kuo P-Y, Ehrmann M, Benedek GB, Loo JA, Klärner F-G, Schrader T, Wang C, Bitan G: Lysine-specific molecular tweezers are broad-spectrum inhibitors of assembly and toxicity of amyloid proteins. J Am Chem Soc 2011, 133:16958-16969.

4. Prabhudesai S, Sinha S, Attar A, Kotagiri A, Fitzmaurice AG, Lakshmanan R, Ivanova MI, Loo JA, Klärner FG, Schrader T, Bitan G, Bronstein J: A novel "molecular tweezer" inhibitor of a-synuclein neurotoxicity in vitro and in vivo. Neurotherapeutics 2012, 9:464-476.

5. Attar A, Ripoli C, Riccardi E, Maiti P, Li Puma DD, Liu T, Hayes J, Jones MR, Lichti-Kaiser K, Yang F, Gale GD, Tseng C-H, Tan M, Xie C-W, Staudinger J-L, Klärner F-G, Schrader T, Frautschy SA, Grassi C, Bitan G: Protection of primary neurons and mouse brain from Alzheimer's pathology by molecular tweezers. Brain 2012, 135:3735-3748.

6. Fokkens M, Schrader T, Klärner FG: A molecular tweezer for lysine and arginine. J Am Chem Soc 2005, 127:14415-14421.

7. Talbiersky P, Bastkowski F, Klärner FG, Schrader T: Molecular clip and tweezer introduce new mechanisms of enzyme inhibition. J Am Chem Soc 2008, 130:9824-9828.

8. Acharya S, Safaie B, Wongkongkathep P, Ivanova MI, Attar A, Klärner F-G, Schrader T, Loo JA, Bitan G, Lapidus LJ: Molecular basis for preventing asynuclein aggregation by a molecular tweezer. J Biol Chem 2014. E-pub ahead of print, doi:10.1074/jbc.M113.524520.

9. Bier D, Rose R, Bravo-Rodriguez K, Bartel M, Ramirez-Anguita JM, Dutt S, Wilch C, Klärner FG, Sanchez-Garcia E, Schrader T, Ottmann C: Molecular tweezers modulate 14-3-3 protein-protein interactions. Nat Chem 2013, 5:234-239. 
10. Dutt S, Wilch C, Gersthagen T, Talbiersky P, Bravo-Rodriguez K, Hanni M, Sanchez-Garcia E, Ochsenfeld C, Klarner FG, Schrader T: Molecular tweezers with varying anions: a comparative study. J Org Chem 2013, 78:6721-6734.

11. Attar A, Bitan G: Disrupting self-assembly and toxicity of amyloidogenic protein oligomers by "Molecular Tweezers"- from the test tube to animal models. Curr Pharm Des 2014. In press.

12. Sinha $\mathrm{S}$, Lopes $\mathrm{DH}$, Bitan $\mathrm{G}$ : A key role for lysine residues in amyloid $\beta$ protein folding, assembly, and toxicity. ACS Chem Neurosci 2012, 3:473-481.

13. Sinha S, Du Z, Maiti P, Klärner FG, Schrader T, Wang C, Bitan G: Comparison of three amyloid assembly inhibitors: the sugar scyllo-inositol, the polyphenol epigallocatechin gallate, and the molecular tweezer CLR01. ACS Chem Neurosci 2012, 3:451-458.

14. Oddo S, Caccamo A, Shepherd JD, Murphy MP, Golde TE, Kayed R, Metherate $R$, Mattson MP, Akbari Y, LaFerla FM: Triple-transgenic model of Alzheimer's disease with plaques and tangles: intracellular $A \beta$ and synaptic dysfunction. Neuron 2003, 39:409-421.

15. Ferreira N, Pereira-Henriques A, Attar A, Klärner F-G, Schrader T, Bitan G, Saraiva MJ, Almeida MR: Molecular tweezers targeting transthyretin amyloidosis. Neurotherapeutics 2014. In press.

16. Zeevi N, Pachter J, McCullough LD, Wolfson L, Kuchel GA: The blood-brain barrier: geriatric relevance of a critical brain-body interface. J Am Geriatr Soc 2010, 58:1749-1757.

17. Banks WA: Drug delivery to the brain in Alzheimer's disease: consideration of the blood-brain barrier. Adv Drug Del Rev 2012, 64:629-639.

18. Zipser BD, Johanson CE, Gonzalez L, Berzin TM, Tavares R, Hulette CM, Vitek MP, Hovanesian V, Stopa EG: Microvascular injury and blood-brain barrier leakage in Alzheimer's disease. Neurobiol Aging 2007, 28:977-986.

19. Farrall AJ, Wardlaw JM: Blood-brain barrier: ageing and microvascular disease-systematic review and meta-analysis. Neurobiol Aging 2009, 30:337-352.

20. Maegawa T, Hirota K, Tatematsu K, Mori Y, Sajiki H: Facile and efficient postsynthetic tritium labeling method catalyzed by $\mathrm{Pd} / \mathrm{C}$ in HTO. $J$ Org Chem 2005, 70:10581-10583.

21. Shelanski ML, Gaskin F, Cantor CR: Microtubule assembly in the absence of added nucleotides. Proc Natl Acad Sci USA 1973, 70:765-768.

22. Lee JC, Timasheff SN: In vitro reconstitution of calf brain microtubules: effects of solution variables. Biochemistry 1977, 16:1754-1764.

23. Loeb W, Quimby FW (Eds): The Clinical Chemistry of Laboratory Animals. 2nd edition. Philadelphia, PA: Taylor and Francis; 1999.

24. Ujiie M, Dickstein DL, Carlow DA, Jefferies WA: Blood-brain barrier permeability precedes senile plaque formation in an Alzheimer disease model. Microcirculation 2003, 10:463-470.

25. Zhang X, Li G, Guo L, Nie K, Jia Y, Zhao L, Yu J: Age-related alteration in cerebral blood flow and energy failure is correlated with cognitive impairment in the senescence-accelerated prone mouse strain 8 (SAMP8). Neurol Sci 2013, 34:1917-1924.

26. Billings $L M$, Oddo $S$, Green $K N$, McGaugh $J$, LaFerla FM: Intraneuronal $A \beta$ causes the onset of early Alzheimer's disease-related cognitive deficits in transgenic mice. Neuron 2005, 45:675-688.

27. Clinton LK, Blurton-Jones M, Myczek K, Trojanowski JQ, LaFerla FM: Synergistic Interactions between $A \beta$, tau, and $\alpha$-synuclein: acceleration of neuropathology and cognitive decline. J Neurosci 2010, 30:7281-7289.

28. Mastrangelo MA, Bowers WJ: Detailed immunohistochemical characterization of temporal and spatial progression of Alzheimer's disease-related pathologies in male triple-transgenic mice. BMC Neurosci 2008, 9:81.

29. Friden $M$, Ljungqvist $H$, Middleton $B$, Bredberg $U$, Hammarlund-Udenaes $M$ : Improved measurement of drug exposure in the brain using drugspecific correction for residual blood. J Cereb Blood Flow Metab 2010 30:150-161.

30. Dagenais C, Rousselle C, Pollack GM, Scherrmann JM: Development of an in situ mouse brain perfusion model and its application to mdr1a P-glycoprotein-deficient mice. J Cereb Blood Flow Metab 2000, 20:381-386.

31. Moss DW: Physicochemical and pathophysiological factors in the release of membrane-bound alkaline phosphatase from cells. Clin Chim Acta 1997, 257:133-140

32. Millan $J$, Fishman WH: Biology of human alkaline phosphatases with special reference to cancer. Crit Rev Clin Lab Sci 1995, 32:1-39.

33. Vardy ER, Kellett KA, Cocklin SL, Hooper NM: Alkaline phosphatase is increased in both brain and plasma in Alzheimer's disease. Neuro-degenerative Dis 2012, 9:31-37.
34. Goldbaum O, Richter-Landsberg C: Activation of PP2A-like phosphatase and modulation of tau phosphorylation accompany stress-induced apoptosis in cultured oligodendrocytes. Glia 2002, 40:271-282.

35. Qiu C: Preventing Alzheimer's disease by targeting vascular risk factors: hope and gap. J Alzheimer's Dis 2012, 32:721-731.

36. Strand BH, Langballe EM, Hjellvik V, Handal M, Naess O, Knudsen GP, Refsum H, Tambs K, Nafstad P, Schirmer H, Bergem AL, Selmer R, Engedal K, Magnus P, Bjertness $E$, Group G: Midlife vascular risk factors and their association with dementia deaths: results from a Norwegian prospective study followed up for 35 years. J Neurol Sci 2013, 324:124-130.

37. Center for Drug Evaluation and Research CfBEaR: Estimating the Safe Starting Dose in Clinical Trials for Therapeutics in Adult Healthy Volunteers. In U.S. Department of Health and Human Services, Food and Drug Administration. 2002. http://www.fda.gov/OHRMS/DOCKETS/98fr/02d0492-gdl0001-vol1.pdf.

38. Reagan-Shaw S, Nihal M, Ahmad N: Dose translation from animal to human studies revisited. FASEB J 2008, 22:659-661.

39. Bourasset F, Ouellet M, Tremblay C, Julien C, Do TM, Oddo S, LaFerla F, Calon F: Reduction of the cerebrovascular volume in a transgenic mouse model of Alzheimer's disease. Neuropharmacology 2009, 56:808-813.

doi:10.1186/2050-6511-15-23

Cite this article as: Attar et al:: Safety and pharmacological characterization of the molecular tweezer CLR01 - a broad-spectrum inhibitor of amyloid proteins' toxicity. BMC Pharmacology and Toxicology 2014 15:23.

\section{Submit your next manuscript to BioMed Central and take full advantage of:}

- Convenient online submission

- Thorough peer review

- No space constraints or color figure charges

- Immediate publication on acceptance

- Inclusion in PubMed, CAS, Scopus and Google Scholar

- Research which is freely available for redistribution 